\title{
Sidney's Certain Sonnets: Speculations on the Evolution of the Text
}

\author{
By GERMAINE WARKENTIN
}

\begin{abstract}
CIR PhInIP Sidney's collection of short lyrics known as Certain Sonnets has generally been treated as a preliminary exercise in the same genre $N$ as his sonnet sequence Astrophil and Stella, but it is difficult to know just how far forward he carried this experiment. As Sidney's modern editor, W. A. Ringler, Jr, wrote in 1962 :

he could not provide the collection with a middle, but his overriding sense of structure at least led him to give it a beginning and an end, for as finally arranged it opens with 'I yeeld, $\partial$ Love, unto thy loathed yoke', and after playing a number of variations on the theme of unfulfilled desire, it concludes with 'Leave me o Love, which reachest but to dust'. 1
\end{abstract}

This lack of coherence is emphasised in the way the collection is titled in each of its three sixteenth-century versions: 'Dyvers and sondry Sonnetes' in the Clifford manuscript $(\mathrm{Cl})$, 'Certein lowse Sonnettes and songes' in the Bodleian manuscript (Bo), and of course Certaine Sonets as the poems appear in the 1998 folio of Sidney's works (98). ${ }^{2}$ Even worse, none of these versions is quite complete: $C l$ lacks $C S$ I and 2, 98 lacks $C S$ s, and Bo lacks $C S$ s, part of $C S$ 28, and all of $C S 29,30$, and 32 . Finally, the arrangement of the poems in Bo is very different from the one shared by $\mathrm{Cl}$, which almost certainly pre-dates it, and 98 , which definitely post-dates it and interestingly does not itself derive from $\mathrm{Cl}^{3}$

From the very beginning, however, Certain Sonnets was regarded as a unit and assigned a particular place among Sidney's works. Various poems of the collection circulated singly, of course, but in none of the 'complete' texts remarked on above are any other poems of Sidney's associated with the canonical 32, and as a group the poems are frequently attached to the

\footnotetext{
1 William A. Ringler, Jr, ed., Tbe Posms of Sir Pbilip Sidhay (Oxford: Clarendon Press, 1962), p. 425 . Hereafter cited as 'Ringler'. In addition see Neil Rudenstine, Sidnoy's Poetic Deaslopment' (Cambridge, Mass.: Harvard University Press, 1967), pp. 11 15-30, 277-83; Robert Kimbrough, Sir Pbilip Sidney (New York: Twayne Publishers, 1971), pp. 101-05; Vanna Gentili's introduction to her edition of Sidney's Astropbil and Stalla (Bari: Adriatica Editrice, 1965), Pp. 101-10; and A. C. Hamilton, Sir Pbilip Sidny: A Stuoty of His Lifo and Works (Cambridge: Cambridge University Press, 1977), Pp. 74-79.

The Clifford manuscript is Folger MS. H.b.1; the Bodleian MS. is Bodleian c Museo 37; the is 98 folio of Sidney's works is STC 22541. Ringler's sigla are used throughout for reference; the recently discovered Ottley manuscript (see note 9 ) is referred to as ' $O$ '. The poems of Cerlain Samets are referred to by Ringler's numbers; none of the early terts is numbered in any way.

'Ringler, p. 425.
} 
Arcadia in various ways that imply they have a connection with that work." Thus, somewhere in the evolution of the collection its contents and - since $9^{8}$ does not derive from $\mathrm{Cl}$ - perhaps even the sketch of a design, were apparently stabilized and given at least provisional sanction as a text.

In what follows I will argue that it is possible to speculate usefully on this process of stabilization by taking a fresh look at the manuscripts of Certain Sonrets; not at the textual variants they record, which have been studied, but at the way in which they were written out. To do so we need to keep two neglected codicological factors in mind. The first is the practical distinction between manuscripts written by professional scribes or secretaries and those produced by amateur copyists of every sort. The second is the way in which the Elizabethans employed their stocks of writing-paper, which was quite different from our practice in the twentieth century. Certain Sonnets is in fact no mere miscellany, and as a codicological analysis will show, the Bodleian manuscript may have had an important role to play in the evolution of its form.

The poems of Certain Sonnets are (except for CS I 2) uniformly amorous in subject matter, but it has not gone unnoticed that they easily fall into small formal and thematic groups. ${ }^{5}$ As the collection stands in Ringler's text these groups seem arranged in a roughly pyramidal structure. Two introductory sonnets (CS I and 2) and two closing ones (CS 3 I and 32 ) provide a frame for the work. The first portion ( $\left.C S_{3-14}\right)$ is composed of four songs written to be sung to well-known tunes and which are paired to frame a quantitative poem, a group of four thematically linked sonnets 'made when his Ladie had paine in her face', and three translations from classical sources. This pattern is roughly mirrored in the last section (CS 23-30) where again four songs frame a quantitative poem, and there are two translations from the modern author Montemayor plus another miscellaneous song. The central section of the collection (CS I -22) comprises poems in a variety of forms, which as Rudenstine noted have a particularly close thematic association. ${ }^{\circ}$ They too have a frame: both $C S$ Is and $C S 22$ draw upon poems of Petrarch with a directness uncommon elsewhere in Sidney.

\footnotetext{
- Ringler, p. 424, noted that Cortain Sown's was attached to three Old Arcadia manuscripts (Cl, $\mathrm{Bo}$, and $\mathrm{St}$ ) and to the same work in the I 998 folio; he took this only as evidence that the poems were written at the same time as the prose romance, and held that the works were not connected (p. rlii). See however Hamilton, p. 75. The Ottley manuscript is composed of a number of poems from Certain Sonwes plus a number of the Old Arcadia poems and a few others. In St, the poems from Certain Sonnats were added some years after the making of the original manuscript; see Sir Philip Sidney, Tbe Countess of Pembroke's Arcadia, ed. Jean Robertson (Oxford: Clarendon Press, 1973), pp. rliv-xlv (hereafter cited as 'Robertson'), and see Ringler, P. 425. And in the 1598 folio, the poems are not appended to the Old Arcadia but to the new. All of these features suggest 2 tenacious connection indeed between the two works.

- Rudenstine, p. 280; Hamilton, p. 75.

- Rudenstine, pp. II6, 279.

' $C S$ Is is based on an impresa, the motto of which is drawn from Petrarch's sonnet 'Pace non trovo'. CS 22 is modelled on the canzone 'Qual piú diverse et nova', which follows directly on 'Pace non trovo' in the Conporiore.
} 
Yet Ringler's version of Certain Sonnets, where we can see this scheme with some clarity, is of course a conflation. To the text of $9^{8}$ (where it is lacking), he has added CS 5, the first of the quantitative poems, inferring its position from the place it occupies in $\mathrm{Cl}$, which is our only authority for the location of this poem. Why is CS s missing from 98, where its absence mars a very apparent attempt at symmetry? Similar questions arise about $\mathrm{Cl}$ and Bo. First, why are the two important sonnets $C S_{1}$ and 2 missing from $\mathrm{Cl}$ ? Ringler thought that since they are in the Italianate manner of Astrophil and Stella they must have been written slightly later than the other poems in $\mathrm{Cl},{ }^{8}$ but it is difficult to read $\mathrm{Cl}$ as a collection without their introductory effect; it dissolves into a mere miscellany despite the presence in it of all the other features of variety and symmetry just described. Furthermore, the recently uncovered Ottley manuscript, in which $C S$ I and 2 appear along with over half the other poems in the collection, may signify they are not quite as late as was thought. ${ }^{9}$ Second, why does Bo record an arrangement of the poems considerably at variance with the one just described, when as Sidney's editors have argued the Arcadia manuscript of which it is without doubt a physical, if not a literary part, was copied at a slightly later date, and very probably from the hypothetical holograph ' $\mathrm{T}_{4}$ ', the working copy of his prose fiction in which Sidney recorded revisions as he made them?10 Finally, in view of the later date of Bo, why does $9^{8}$ preserve a version of the collection which returns to the form represented in $\mathrm{Cl}$ ?

To resolve these problems, we need a working hypothesis as to the nature of Sidney's holograph of Certain Sonnets. Here the character of its manuscripts comes to our aid, for $\mathrm{Cl}$ and $\mathrm{Bo}$ are scribal copies, in contrast with the many other extant manuscripts of individual poems or groups of poems from the collection. That is, they were written out by professionals perhaps hired scribes or household secretaries - whose business it was to copy what was put before them exactly as they found it, rather than by amateurs who entered in their private miscellanies what was prompted by personal taste or casual opportunity. Thus we can with some discretion infer from $\mathrm{Cl}$ or $\mathrm{Bo}$ what may have been the arrangement of the papers from which they were transcribed. But the other sources in which groups of Certain Sonnets appear all seem to be amateur compilations, and are of a very miscellaneous nature (see Appendix). Though they are valuable testimonies to the texts of individual poems, it is doubtful if they can, without supporting evidence, be used to reconstruct the arrangement of the poems in the originals from which they were copied.

\footnotetext{
- Ringler, pp. 423, 425 .

- Peter Beal, 'Poems by Sir Philip Sidney: The Ottley Manuscript', Tbe Library, v, 33 (1978), 284-95. See Appendix.

${ }^{10}$ Robertson, p. 1v; Ringler, p. 370.
} 
If this is so, what information then can $\mathrm{Cl}$ and $\mathrm{Bo}$ be made to disclose of the originals from which they were transcribed? $\mathrm{Cl}$, the Clifford manuscript, is held by Ringler and Robertson on the basis of internal evidence to be a third redaction of the Old Arcadia which Ringler dates in 1 981.11 The manuscript is gathered very regularly in eights, except for two individual bifolia at the end, and is written on two papers, one with a watermark not yet identified (ff. I-86) ${ }^{18}$ and the other on unmarked paper (ff. 87-226). Certain Sonnets begins within the final gathering, on folio $216^{\circ}$, and is completed on the second of the two terminal bifolia. The gutters of the later gatherings have been much mended, and there are no watermarks, but felt-side and mould-side correlations establish fairly reliably that there are no cancels in folios 216-226. There is no indication in the manuscript of the name or status of the copyist (such as the scribe's paraph which concludes Bo), but the hand is strong, elegant, and regular, and Ringler regards it as a 'fine late sixteenth-century professional hand'. ${ }^{13}$

It seems clear that in $\mathrm{Cl}$ Certain Sonnets was not a last-minute addition to fill out an unfinished quire, but was planned to form part of the whole manuscript. However, the scribe was not organizing his use of paper very far ahead as he approached the end of his task, since he did not make a single gathering of the two terminal bifolia. Nevertheless he does not seem to have been under any pressure as a result, since $C S 27$, one of the longer songs, is begun at the bottom of $224^{\mathrm{v}}$ and finished on $225^{\mathrm{r}}$ with no indication that it was an afterthought, and without crowding. There is some slight evidence of crowding on the rest of ff. 225-26, however, as the scribe made sure to complete his copy without taking yet another sheet. Taken as a group, these points suggest that Certain Sonnets as it appeared in $\mathrm{Cl}$ was being copied from an original which the scribe had before him all at one time and in an arrangement he could interpret without difficulty.

Bo, the Bodleian manuscript, preserves a fourth redaction of the Old Arcadia, and Ringler estimates it was copied late in I $8 \mathrm{8}$ or early in is 82.14 In it, the poems appear - or did once appear - in the following order: $1,2,19,16 a, 16,17,18,19,20,21,31,22,23,24,25,26,27,28$ (in part), 3, 4, 6, 7, 8, 9, I0, I1, I2, I3, 14. The copy is no longer perfect; one leaf has dropped out, and as a result CS 26 and parts of 25 and 27 are missing, though it is clear they were once present. As I noted earlier, CS 28 is incomplete, and $C S 5,29,30$ and 32 are missing. Bo is a professional copyist's work; it is not as good-looking as $\mathrm{Cl}$, but it is signed with a scribe's paraph or professional signature, not yet identified.

11 Ringler, pp. 369-70, 423. See also Robertson, pp. lii-lvi for the relationship of the texts and P. xvii for a general indication of their dates.

is Ringler, pp. $367,525,527$.

12 Ringler, P. 527. I am indebted to Malcolm B. Parkes for alerting me to the significance of scribes' paraphs.

14 See note II above for the relationships of the texts, and Ringler, p. 367. 
Ringler holds that the arrangement of the poems in the Bodleian manuscript is the result of an accident; in his view Bo comprises a text in which the 'preferred sequence' of Certain Sonnets, testified to by $\mathrm{Cl}$ and 98, was inadvertently disrupted: 'the varied order of the poems in Bo and St indicates that Sidney kept his miscellaneous songs and sonnets in a portfolio on unbound separate sheets of paper that could easily be disarranged', he observes, and concludes that for Certain Sonnets 'there are no textual problems of any complexity.'15 Since he treats Bo and St in the same way, it is apparent that Ringler here is not distinguishing between the scribal transcription of Bo and the amateur transcription of the Certain Sonnets section of St. In the case of Bo, he was of course justified in inferring the arrangement of the original from the nature of the copy. But when we consider Renaissance writing practices in general, and what can be ascertained of Sidney's in particular, we realize how unlikely it is that the holograph of Certain Sonnets came to the scribe of Bo on separate sheets, or even in a portfolio.

Sidney and his contemporaries did not write on pre-cut single sheets as we do today, but on folded folio sheets or bifolia. Single sheets of quarto writing-paper first appeared in the early seventeenth century (one is described by Croft in his discussion of Donne's hand) ${ }^{\mathbf{1 0}}$ but they were still rare at its end; Congreve's Sir Wilful Witwoud remarks, 'By'r Lady, I conjectured you were a fop, since you began to change the style of your letters, and write in a scrap of paper, gilt round the edges, no broader than a subpoenal'. Individual leaves can certainly be found in the archival collections of the period as well as in the rare bodies of literary papers such as those of Drummond of Hawthornden and William Fowler (Nat. Libr. Scot. Mss. 2053-2067), but the modern eye notes immediately that bifolia are far more common even when the material is very miscellaneous, and in correspondence and continuous writing are generally the rule.

Furthermore, Elizabethan writing and printing paper was both scarce and expensive; stocks had to be imported from the continent, and it was so costly in the is 80 s that Thomas Churchyard wrote a poem of praise on the founding of an English manufactory. ${ }^{17}$ Even the unmarked paper of ff. 87 to 226 of $\mathrm{Cl}$ tells a story: paper without a watermark was always of a lower grade, ${ }^{18}$ and its use shows that whoever wrote $\mathrm{Cl}$ was paring costs, or that stocks were low where the manuscript was being copied (perhaps in the country?) and this was all that could be obtained. Every scrap of paper was used and re-used, as the Fowler papers so comically illustrate, and it is not likely that a poet would regularly have drafted poems as short as those

16 Ringler, p. 42 s.

16 P. J. Croft, Awtograpb Poetry in the Englisb Language (New York: McGraw Hill, 1973), I, 25.

${ }^{17}$ Thomas Churchyard, 'A Description and playne discourse of Paper', reprinted in John Nichols, Tbe Progresses and Psolic Pracessions of Queen Elizabetb (London, 1832), 11, 592.

is Allan Stevenson, Tbe Problem of the Missale Speciale (London: The Bibliographical Society, I 967$),$ p. 90 . 
in Certain Sonnets on bifolia and left the conjugate leaves entirely unfilled unless he were very rich, which Sidney emphatically was not. Thus, the 'papers' of a writer in the sixteenth century would only exceptionally have consisted of single pages in a folder, or quantities of single poems one to a bifolium. Much more likely would have been bifolia fairly heavily written over, and quired paper books or vellum-bound notebooks in which material had been drafted or recopied.

In addition to the technical requirements of his medium, the Renaissance copyist had personal habits in writing which sometimes have to be penetrated. Just as we learn to interpret the way in which the problem of imposition was handled by early printers, so we must come to terms with the habitual ways in which individual writers of manuscripts - no longer subject to the regimes of the medieval scriptoria - handled the bifolium, the assembling of unquired bifolia, the use of the pre-quired booklet, and the gathering of bifolia on one scheme or another determined by the scribe's personal habit or contingencies encountered in the course of writing.

The layman, of course, had some of the same technological problems as the professional scribe, and certainly possessed habits of his own in using paper. Like his contemporaries Sidney regularly used bifolia in correspondence. His letters show that though schoolboy neatness gave way in maturity to a more casual manner, his writing habits were on the whole consistent throughout his life. His deathbed scrawl to Johan Weyer, like the neat missive he despatched to Cecil in his fourteenth year, was written on a bifolium, and among the fifty-seven letters in his hand I have seen (of approximately ninety-one extant) only two employ a torn leaf (revealed when an address appears on the verso of a single correspondence leaf). ${ }^{10}$ Of lengthier manuscripts in his hand we have only one, the rapidly composed Defence of the Earl of Leicester (Pierpont Morgan Library MS. 1475), and it is written on unquired bifolia. In fact when Sidney told his sister in the dedication of the Arcadia that his narrative had been written 'in loose sheets of paper'20 he probably meant not that he had written his work out on single leaves, but that he was sending bifolia to the Countess of Pembroke and that they too were unquired. In addition to his habitual use of bifolia, Sidney was sparing of paper when he could be. He sometimes filled the margins of his letters with long postscripts written crosswise, and in writing the Defence of the Earl of Leicester he crowded his script cruelly, and used the versos as well as the rectos, a practice often avoided in non-

13 To Weyer, PRO State Papers Foreign: Holland, v. Io no. 73. To Cecil, PRO State Papers Domestic: Elizabeth, v. 49 no. 63 . The two letters written on torn leaves are PRO State Papers Foreign: Holland, $\mathbf{v}$. \& fol. 102 (to Walsingham, Nov. 23, i 58 s) and PRO State Papers Foreign: Holland. $v .7$ fol. 83 (to Walsingham, Mar. 19, i 86). The two leaves of the 'Discourse on Irish Affairs' (BM Cotton Titus B xIr, fols. 564-65) were probably also conjugate.

so Robertson, p. 3. 
professional writing even in a paper-saving age because of the corrosive effects of the inks then in use.

No evidence exists to show whether in drafting his poems Sidney would have exhibited the habits he displayed elsewhere; Aubrey of course reports that he often used his 'table booke' to record ideas for the Arcadia when he was hunting, but unfortunately the only poem extant in his own hand is written in a printed book. ${ }^{21}$ But since his writing habits where we can assess them are both orderly and conventional even when he was writing under pressure, it seems reasonable to suppose that his poetic manuscripts would somewhat resemble those of his contemporaries which are available to us. There are of course surprisingly few holograph manuscripts by poets of distinction in Tudor and Stuart England, but the very little that exists supports the view that poems were drafted, revised, and even re-arranged on bifolia used singly or gathered in paper books or quires. ${ }^{22}$ If the much richer evidence left by Sidney's Italian contemporaries may be used as a guide, the writer's aim was to produce not a fair copy of a single short poem, but a reference collection of his own work to which he could turn again and again to enter new poems and revise old ones. Only with Michelangelo do we notice a significant departure from this practice. ${ }^{23}$

The only extensive holograph manuscript of any Tudor poet (if we except the Egerton manuscript - only partly in Wyatt's hand - and certain 'fair

1 Croft, I, 14. For Sidney writing at the hunt see John Aubrey, Briof Lives, ed. Andrew Clark (Oxford: Clarendon Press, I 898), I, 248. Sidney actually mentions a paper book in $N A$ II, ch. II, where he tells us Amphialus' spaniel, rummaging in the discarded clothing of the bathing princesecs, 'lighted upon a little booke of foure or five leaves of paper'. (Tbe Prose orks of Sir Pbilip Sidno, ed. Albert Feuillerat, 1: Tbe Conntesse of Pembroke's Arcadia, Cambridge: The University Press, 1965, p. 222.)

* I use the evidence provided in Croft, I, but since Croft does not supply collations I have supplemented his accounts with my own investigations where I could. If we cxclude scribal and autograph 'fair copies' like those of Wyatt, Sackville, Greville, Gorges, and Harington, we find that the surviving fragments in the hands of Skelton, Raleigh, Southwell and Browne all show signs of composition on bifolia. In the same period the Fowler papers contain many single leaves. However, Fowler's nephew, Drummond, used bifolia individually and in gatherings for composition and for fair copies (insofar as we can judge this after Laing's nineteenth-century rebinding). Croft gives later samples of drafts by Donne and Herrick, both of which are on single leaves. For Robert Sidney's reference collection, see the discussion which follows above.

a The very full records left by Sidney's Italian near-contemporaries illustrate how this was done. For example, of the two mss. of Gaspare Visconti's poems (ca. 1490; Milan: Bibl. Trivulz. 1093 and 2157 ), the first is a paper notebook where rough drafts and fair copies are mixed together, the second a magnificent presentation canzoniere containing some of the same pocms. Ertensive evidence of a poet's continuous revision of his work appears in the manuscripts of Celio Magno (1 536-1602) in the Bibl. Marciana and the Bibl. Correr in Venice. These are prevailingly in quires, but the poet nevertheless vigorously revised them by means of marginal instructions as to their arrangement, correction of the tert itself, and even the cancellation of pages by penstroke and excision. The rime of Michelangelo (Archivio Buonarroti, on deposit in the Bibl. Laurenziana, Florence), are unusual, often being written on scraps of paper torn, folded, and sealed. I suspect this exceptional practice arose because Michelangelo, who usually sent his poems as missives, had an artist's rather than an author's perception of the function of paper, and when he was writing simple tore bits from the sketching paper at hand in his atelier. For an interesting account of the history of the papers of two poets who treated their 'reference collections' somewhat differently ece Margaret Crum, "Notes on the Physical Characteristic of Some Manuscripts of the Poems of Donne and of Henry King', Tbe Library, v, 16 (1961), $121-32$. 
copies' made or corrected by Sackville, Greville, and Gorges) is just such a reference collection; it was compiled by Philip Sidney's brother Robert in the decade after the elder poet's death. Kelliher and Duncan-Jones ${ }^{24}$ show that the Robert Sidney manuscript (B.M. Add. 58435) was originally a quarto notebook, and that it was ruled with red margins before Robert started to use it (indicating to me that he perceived it as a unit and intended to use it as such), but that as he worked he regularly altered his copy by excising leaves. The poems form a continuous sequence, but they seem to bear several series of numbers, indicating either complex revision of the order of the poems or the imposition of some scheme or schemes lost to us now. Beside the sonnet on $f .4^{\nabla}$ is the marginal annotation "This should bee first', indicating that the poem was to be read in a different place than the one it actually occupied. The Robert Sidney manuscript exemplifies a common European codicological type in its period: the holograph reference collection of lyrics made up and used as a single notebook but tinkered with continuously as the poet attempted to turn the diverse products of his invention into something approaching a polished work of art. Such a collection, with its penstroke cancellations and marginalia may often have posed a difficult task for a scribe to copy, one much different from the relative continuity of a manuscript of prose or a longer poem.

Despite the fact that as yet we have no continuous poetic manuscript in Philip Sidney's own hand, the picture painted here suggests that neither the original drafts of the poems of Certain Sonnets, nor their fair copies if such were made, are likely to have existed in a format in which the poems could have been shuffled independently as Ringler seems to think they were, at least without producing a great deal more random disorder than occurs in Bo. For a close examination of the sequence of the poems in that manuscript reveals that very little shuffling has actually taken place. Apart from the absence of $C S$, (missing also from 98) and the omission of three poems from the end of the collection, many features of the arrangement of $\mathrm{Cl}$ and 98 are in fact preserved in Bo. A moment's contemplation shows very simply that the group of poems in a varied arrangement has been moved to the beginning of the collection, and the songs, quantitative poems, translations, and the sonnets on his lady's pain have been gathered together at the end. Besides CS 5, part of CS 28 and all of $C S 29,30$, and 32 are of course missing, and $C S 31$, one of the two terminal sonnets rejecting love appears not at the end of the collection, but just after three poems (CS 19-21) linked by the theme of farewell or absence. Furthermore, a close examination of the actual makeup of the Bodleian manuscript reveals so much evidence of the scribe's struggle with his material that we have to

\footnotetext{
M Hilton Kelliher and Katherine Duncan-Jones, 'A Manuscript of Poems by Robert Sidney: Some Early Impressions', Britisb Library Jowrnal, I (1975), 107-44.
} 
conclude that he was striving to copy exactly a prototype which ordered the poems in this way.

The Bodleian manuscript is made up of sixteen quires. The first eight are regular in composition: six sheets each, bearing a watermark like Briquet I ros 5. The second eight (probably Briquet I 2775) are very irregular, varying from 9 to 13 sheets in quires 9-14, with only six sheets in quire 19 . Quire 16 begins at $f$. 240 and runs to $f$. 246 . One leaf, which we will call $24 \mathrm{Ia}$, is as I have already noted missing. It must have dropped out at an early date, since the foliation, which is unlikely to be later than the seventeenth-century binding, ignores it. Quire 16 ought, then, to be a gathering of four leaves. Close examination of the watermarks and the binding of the manuscript shows however that ff. 240, $24 \mathrm{I}$ and 242 all bear watermarks and are single leaves tipped directly into the binding. Folios 240 and 242 cannot therefore have been conjugate, and though we cannot know whether it too was watermarked, it is very doubtful that the missing $24 \mathrm{Ia}$ was conjugate with $24 \mathrm{I}$; since it fell out so early, it was probably a single leaf as well. The two sheets composing ff. 243-246 constitute a single, separate gathering. The so-called quire 16 , then, was originally composed of at least two and probably four cancels, plus two more sheets folded and gathered. Bo is thus made up of eight small regular gatherings (I-8), six large but relatively irregular gatherings (9-14), one very short one (IS) and one especially devised in the face of some unknown contingency (16).

Briefly summarized, it appears that the scribe began to copy Certain Sonnets in quire Is, and proceeded as far as $C S_{31}$, of which he completed all but two lines. He then began quire 16 with the last two lines of $C S_{31}$, and continued to copy, entering $C S 22,23,24, C S 25$, probably $C S 26$ and $C S 27$, covering in the process four folios. What he then wrote must have been both extensive and unsatisfactory, for he apparently cut all of ff. 240, 24I, $24 \mathrm{Ia}$, and 242 from their conjugate leaves, which he then rejected. Preserving ff. 240-242, he then continued writing on a small gathering of two sheets until he finished his task, copying out part of $C S_{28}$, and then adding $C S_{3-14}$. On f. $246^{\mathrm{r}}$ he finished with his personal 'paraph' or sign of formal completion, indicating that whatever he was copying from, he was sure enough that he had transcribed it exactly as it was handed to him to put his official signature on the finished job.

There are two conclusions to be drawn from this. The first is that the attempt at correction and the presence of the paraph indicate that the positioning of $\mathrm{CS}_{23-28}$ and $\mathrm{CS}_{3-14}$ in Bo is a feature of the original from which the scribe was copying, not an idiosyncrasy of Bo itself, and that the scribe of Bo regarded the arrangement of his prototype as having some sort of authority. The second point is that of course the copy he made was not correct. One poem is incomplete, and three others are missing. What are we to make of this conflicting evidence, which at once ratifies the legitimacy 
of Bo as a copy and at the same time exposes its limitations as a text?

The explanation lies, I think, in the probability that the scribe was following an authorized but extremely confusing copy: a bundle of bifolia with cross-references directing the re-arrangement of the poems, or perhaps a version of $\mathrm{Cl}$ with $\mathrm{CS} \mathrm{I}$ and 2 added to it, plus some marginal instructions for revisions in the poems' order. If the scribe had been working with a reference collection of this sort - we will call his prototype ' $\mathrm{X}-\mathrm{Bo}^{-}$' - he probably proceeded in the following way.

As we saw, the scribe began his copying of the poems part way through quire I s. Finishing the Arcadia on 236 $6^{\mathrm{p}}$, he turned on $237^{\mathrm{r}}$ to Certain Somets, almost certainly as in $\mathrm{Cl}$ planned as part of the whole manuscript. He had in his hands at this point only enough paper to copy to the end of $\operatorname{CS} 31$, that is, to copy $C S$ I and 2, IS-2I, and $3 \mathrm{I}$, and since quire IS is so short, this is probably exactly the way he planned it. He copied $C S$ I and 2, encountered a note in X-Bo directing him to $C S_{\text {I }}$-2I, and copied them. He was then directed to the end of $\mathrm{X}$-Bo to pick up $C S 3 \mathrm{r}$, which he did, finishing by the end of quire is all but two lines of $C S S_{3}$. The fact that he had only allowed himself enough paper to get this far suggests either that he thought that was all he had to copy from X-Bo, or that the instructions written in X-Bo treated the poems that follow $C_{3} S_{3}$ in some very different fashion. We have already noted that in the Bodleian arrangement of Certain Sonnets it is roughly at this point that the miscellaneous songs and translations begin. Some such division may have been made clear in X-Bo; in any case, it is apparent that if the scribe was responsible for the number of leaves in quire is, he made an effort to get $C S_{1}$ and 2, $C S_{\text {I S-21, and } C S_{31}}$ written at the end of the Arcadia, and had provided for no other poems.

The verso of $f_{.} 239$, the last leaf of quire is, is crowded, but it is apparent that by the time he wrote it the scribe realized that there was after all more to do, and was content to carry two lines of $C S_{3}$ I to the top of the new gathering on which he would copy out the remaining poems. He then assembled four sheets and went on working, copying $C S_{22-27}$, plus enough material to fill four more leaves. Either these leaves were incorrectly copied, or some accident then befell them. In any event, the scribe cut them out, leaving $240,24 \mathrm{I}, 24 \mathrm{Ia}$, and 242 to stand as they were written. Then for the third time he assembled paper ad boc, this time gathering two sheets. On these he copied part of $C S 28, C S$ 3-4, and $C S 6_{-14}$, and then concluded his work with his paraph.

We are left with the question of why $C S 5,28,29,30$, and 32 are missing or imperfect in Bo. One unifying feature of the separate problems they pose is that all of them ought to have appeared in the portion of the manuscript the scribe was forced to correct. I can offer no explanation for the absence of $C S$ s, except that since it is also missing from 98 , it may have been over- 
looked accidentally in some earlier copying. To drop it deliberately would have disturbed the symmetrical aesthetic scheme we have discerned in $C S$ 3-7 and CS 23-27. However, Sidney was never over-rigid, and $C S$, is an early and undistinguished poem. He may simply have decided to reject it regardless of the effect on his scheme. It is not possible to be sure why CS 28 is truncated and CS 29 missing. It may simply be that the scribe, confused by the accident that befell the cancelled leaves, botched $C S 28$ and dropped CS 29 as part of the same error when he took up his new gathering; the penstroke he often used to conclude a poem appears at the end of $C S 28$, suggesting he thought he had copied it all. The best we can say is that at this point X-Bo may have contained one of the following arrangements: part of $C S 28$ only, all of $C S 28$ plus $C S 29$, or (also a possible source of confusion) CS 28 and 29 with a marginal note directing the scribe to group them with the other translations, $C S_{12-14}$, yet to be copied. It is not clear quite which is the case; we can be sure, however, that in counting out his paper, the scribe left room for $C S 28$ and 29, but not for $C S_{30}$ and 32, and certainly not for the copying of all four poems, for the remaining it blank pages make available that much space and no more.

This suggests to me that when the scribe made reference to X-Bo for the purpose of calculating how much paper he still needed he remembered he had to copy $C S 28,29$, and $C S_{3-14}$, but confused by having had to cancel four leaves and catching sight of annotations beside CS 3-14 such as 'put these at the end', he forgot CS 30 and 32 and simply left them out. He drew his paraph after $C S$ i4 because having reached the already copied $C S$ is in X-Bo (if he followed custom, he would have stroked it out after copying it) he thought he was finished. I do not suppose that X-Bo was an imperfect version and lacked $C S_{30}$ and 32 . I think that though $C S_{31}$ had been sent to do service elsewhere, the two remaining terminal poems were still supposed to form the conclusion of the collection, and would have done so if the scribe of Bo had been following a more or less straightforward original instead of the confusion of a collection of separate lyrics re-ordered by marginal annotation.

From this speculative attempt to reconstruct the copying of Bo two points emerge. First, we can no longer be sure that X-Bo was accidentally disordered as Ringler suggested. Elizabethan writing practice and the absence of purely random disorder makes it more likely that the prototype of Bo was either an annotated paper quire or vellum-bound notebook, or a bundle of bifolia fairly heavily written and then annotated in the margin, and not the file of single poems Ringler imagined. Second, the very imperfections in Bo itself go far to show that it is an authentic, if imperfect copy of its prototype.

What then is the aesthetic significance of the changes which turned the ornate symmetry of Certain Sonnets in the $\mathrm{Cl} / 98$ version into the apparent disorder of Bo? There are only three literary features of Bo we can point 
out in a short space. The first is that in uniting the prefatory poems $C S_{I}$ and 2 to the poems in a varied arrangement, $C S$ I -22 , Sidney brought the design of the first part of the collection closer to that of his soon-to-bewritten Astrophil and Stella, which on the model of many continental canzonieri is composed of sonnets irregularly interspersed with longer poems of different lengths. The second is that in grouping the more miscellaneous poems - the songs, sonnets and translations - at the end, the Bodleian manuscript follows again a model apparent in large numbers of European collections of the same type, where after the opening lyrics with their frank imitation of Petrarch's Canzoniere, the work develops a more miscellaneous cast and terminates weakly in a hodge-podge of unrelated poems.

Third, the placing of $\mathrm{CS}_{3} \mathrm{I}$, a firm rejection of love, among several poems in which the poet has struggled in various ways to leave off loving, seems to me persuasive evidence that a deliberate reorganization of Certain Sonnets was in hand when Bo was copied out, and that Sidney was its source; it is improbable that mere accident caused it to fall into a place so thematically secure. Indeed, the architectonic impulse behind Bo as a whole seems to me plainly authorial. As the manuscript evidence suggests, it is no longer necessary to regard Bo as disordered and unreadable. Rather, I contend, it records the revision Sidney made of the poems collected in $\mathrm{Cl}$, a revision made on principles which were leading him by a process of experimentation towards the variety of organization, fluidity of design, and narrative strength of Astrophil and Stella.

One problem still presses, of course. If the Bodleian manuscript of Certain Sonnets is the most evolved version of that collection, why does the folio text of 1598 reproduce the Clifford arrangement of the poems with the addition of $C S I$ and 2, rather than the one we see in Bo? Did Sidney reject his revision and return to the earlier arrangement? I think it more likely either that $\mathrm{Cl}$ once contained $C S \mathrm{I}$ and $2,{ }^{25}$ or that 98 preserves a version of Certain Sonnets produced in the months between $\mathrm{Cl}$ and Bo. Certainly the history of the collection is much more complex than the extant manuscripts would indicate, for a combination of codicological and textual evidence suggests that as many as ten bodies of Certain Somnets could have existed in the is 80 : $\mathrm{Cl}, \mathrm{X}-\mathrm{O}, \mathrm{X}-98, \mathrm{X}-\mathrm{Bo}, \mathrm{Bo}$, and possibly the originals of $\mathrm{Ma}, \mathrm{Di}$, $\mathrm{St}, \mathrm{Hn}$, and $\mathrm{Hy} / \mathrm{Ra}$. The individual circulation of twenty-seven of the poems of Certain Sonnets in manuscript in that decade and the one following testifies to the fact that some of the poems at least were widely known, and if the collection itself was as familiar, it may have been in the form best

\footnotetext{
is Since CS I and 2 appear in the Ottley Ms., it is possible that they were written slightly earlier than Ringler thought (see Ringler, p. 423). Thus they may have been intended for the version of the collection copied in $C$, but accidentally omitted. It is easy to explain how this might have happened; the $\mathrm{Cl}$ scribe was 'prone to eye-skip' (Robertson, $\mathrm{p}$. v), and if the two poems occupied the firat of a bundle of bifolia, they may simply have got lost. However, it is not so easy to explain how the omission went uncorrected.
} 
known in $\mathrm{Cl}$ and 98 . It is possible that Bo, precisely because it was a late and perhaps unfinished revision, was never widely circulated, and little time intervened between its drafting and the development in Sidney's mind of the much more exciting enterprise of Astropbil and Stella. By I 998 , when the manuscripts for the folio were assembled, not even those who had been closest to Sidney may have been entirely clear as to which of the extant versions of an embryonic work, tinkered with sixteen years before and then set aside, was the authoritative one. And indeed, the ornate pyramidal design of the $\mathrm{Cl} / 98$ version reflects very satisfyingly Sidney's response to the strategies by which Googe, Turberville, and Gascoigne had assembled lyric collections in the decades just previous; in no sense is that version of Certain Sonnets an unfinished work. It would not be surprising if those who chose the manuscripts from which $9^{8}$ was prepared thought that Bo was just a mangled transcription; they had ample reason to do so.

Whatever Sidney was doing with Certain Sonnets in the winter of is $81-82$, he abandoned it the following summer to compose one of the three most distinguished sonnet sequences of the English Renaissance. In a future essay I hope to show how the experimentation revealed in the Bodleian manuscript of Certain Sonnets allowed Sidney to formulate certain aesthetic decisions about the genre of the Renaissance lytic collection or canzoniere which deeply affected his approach in the much greater experiment of Astrophil and Stella.

\section{Toronto}

\section{Tbe Ottley Manuscript}

\section{APPENDIX}

The Ottley manuscript ('O') of poems by Sidney was first described by Peter Beal in The Library, $\mathrm{v}, 33$ (1978), 284-95. Besides poems from $O A$ and six other lyrics (attributed and not yet attributed) it contains 18 of the 32 Certain Sonnets (plus Dyer's $16 \mathrm{a}$ ). This is a tantalizingly large number, but not large enough to warrant considering $\mathrm{O}$ a 'more or less full' manuscript of the collection. The poems in the manuscript are mingled in an arrangement which bears no resemblance (either as a whole or in terms of the individual works involved) to the order of any other known text. Dr Beal remarks, 'the poems appear to have been copied at random, without any logical sequence; this suggests that the copy-text was either a similar anthology or else a series of poems on separate sheets of paper' (p. 28s).

Photocopies kindly provided me by $\mathrm{Dr}$ Beal show that the poems are written in an extremely regular Elizabethan secretary hand, possibly scribal, and certainly that of a practised penman. There are a number of terminal flourishes, but none resembling a paraph. Though the hand is conventional, the form of the manuscript is very curious. In origin it apparently consisted of three bifolia, each of which was individually folded in half and stitched along the open edge to form a packet for 
delivery to someone. The leaves of one of the bifolia are no longer conjugate but $\mathrm{Dr}$ Beal assumes they once were.

As a consequence of its form, it is hard to surmise what the order of the manuscript's original may have been, since we do not know in what order (if any) the three packets were intended to be read. The variants in the manuscript have been interpreted differently by $\mathrm{Dr}$ Beal, who thinks $O$ derives from early drafts of Sidney's poems which may have been on loose sheets or else in the form of an anthology in the order we find in Ottley, and by Jean Robertson (Tbe Library, VI, 2 (1980) 202-05) who holds that O reveals affiliations with the Group III manuscripts of $O A$. It is not impossible that 'a similar anthology' was the original from which the copyist of $O$ worked but since we know of no other in this form, we can only speculate on what kind of manuscript that might have been. The view that random copying necessarily indicates the presence of a source on loose sheets which can be rearranged at will is of course countered in the main argument of my essay. And if the poems originally had the same order as a manuscript like $\mathrm{Cl}$, it is very clear that in transcribing them, the copyist completely disregarded that order.

I suspect that despite the confidence and regularity of the hand, we have in $O$ an extreme example of the non-professional copyist's tendency to copy whatever poems he liked in any order that suited him. The most interesting new information about the construction of $C S$ which appears in $\mathrm{O}$ is the fact that the motto Splendidis longum valedico nugis appears after $C S 25$, and a new and heretofore unknown motto, $V$ irtus secura sequatur follows $C S$ 32. The Ottley manuscript appears to hold much promise for students of Sidney's text.

\section{Other Manuscripts Containing Several Poems}

Besides $\mathrm{Bo}, \mathrm{Cl}, 98$, and $\mathrm{O}$, only six of the substantive manuscripts and prints of Certain Sonrets contain enough poems to provoke speculation on the arrangement of their originals. These are Ma, Di, St, Hn (all of which Ringler's analysis of variants shows to have independent origins) and $\mathrm{Hy}$ and $\mathrm{Ra}$ (which may come from the same source).

Ringler holds that Ma (Marsh's Library, Dublin, Z 3.9.21) originated from a source similar to but not the same as $\mathrm{Cl}$ (p. 560) and $\mathrm{Di}\left(\mathrm{STC}, 66_{3} 8\right.$ ) came from a source nearly identical with 98 (p. 564 ). Ringler implies that St (St John's College, Cambridge MS. I. 7 [James 308]) had a similar original, but does not explain what this source was or how it came to be consulted so haphazardly and possibly so tardily by whoever added ff. [ii]-[iii] to $\mathrm{St}$ after $\mathrm{I}_{3} 32$. Ma, a poetical commonplace book in a number of hands, has $C S_{19}, O A_{17}, C S_{23}, C S_{22}$, and $C S_{19}$, in that order, on ff. $17^{\nabla}-19^{v}$. Di has $C S 8-11,1-2,18,20$, in that order, on $\mathrm{ff} . \mathrm{C}_{3}^{\mathrm{v}}-\mathrm{D}_{4^{\tau}}$. If, as with their verbal texts, the order of the poems in each case was originally like $\mathrm{Cl}$ or 98 , it is clear that some principle of selection has entered in at the point of writing (in the case of $\mathrm{Ma}$ ) or at or before the point of printing (in the case of Di). In St the poems appear in the order 19, 6, 5, 3, and 30; again selection is apparent, and we have even less evidence for guessing from what sort of text the selection was made. Hn, edited as The Arumdel-Harington Manuscript of Tudor Poetry by Ruth Hughey (Columbus: Ohio State University Press, 1960), contains $C S_{3}, 1,27$, and 30 in that order. $C S_{3}$ and $\mathrm{I}$ are on leaves widely separated from 
each other and from CS 27 and 30; $\mathrm{CS}_{3}$ is in Sir John Harington's hand, the other poems in a different writing. Clearly no conclusions about the arrangement of their original can be drawn from its testimony.

$\mathrm{Hy}$ and $\mathrm{Ra}$ constitute a special case, since they appear (with Bn, containing only $C S$ I $6 \mathrm{a}$ and 16 , and Fo, containing only $C S_{3}$ ) to descend 'through two or more intermediaries from 2 corrupt common ancestor, perhaps a sheaf of 13 or more Certain Sonnets on separate sheets of paper which Sidney allowed to be copied by one of his friends who then further circulated them' (Ringler, p. 425). Bn and Fo contain too few poems to surmise the order of their original. Hy (BM Harley $7392[2])$ had a single compiler, but the poems appear in the order $16,16 \mathrm{a}, 30,19$, 3, 23, and are interspersed with poems by others. Ra (Bod. MS. Rawl. poet 8s) also was compiled by one person; here the poems appear in the order $16 \mathrm{a}, 16,3$, 19, $21,23,8-11,25$ (in part), 22; both 21 and 22 are misattributed, and the poems are interspersed among the poems of other authors. It is clear that neither in $\mathrm{Hy}$ nor $\mathrm{Ra}$ did the compilers set out to transcribe $C S$ as a work. From the duplication in poems between the two manuscripts we might conclude that their common original had a restricted number of poems, but it is worth noting that 3, 30, 16a, 16 , I9 and 23 were among the more frequently copied of the $C S$ poems in circulation (19, 3 and 30 also appear in St, for example) and there is as much reason for suggesting that both copyists, working from a bad transcription of the whole collection, picked out current favourites for their own manuscripts, as for arguing that their original was limited to those poems and a few others. 